Consuelo Campos Campos

Universidad de Concepción, Concepción, Biobío, Chile

Lucía Saldaña Muñoz

Universidad de Concepción, Concepción, Biobío, Chile

\title{
Relaciones de género y arreglos en parejas de profesionales: ejecución v/s responsabilización
}

Resumen: Este artículo muestra los resultados de una investigación empírica cualitativa, que aborda las relaciones de género y los arreglos domésticos configurados en hogares de parejas de profesionales del Gran Concepción urbano, Chile. Se problematizan elementos biográficos, expectativas profesionales y desarrollo laboral, con elementos teórico-contextuales, de modo a caracterizar cómo se desarrollan las dinámicas y rutinas domésticas entre los integrantes de estas familias. A partir de los testimonios, se identifican hallazgos que permiten sostener la persistencia de elementos adscritos al modelo tradicional-patriarcal de distribución de roles domésticos, como también algunos cambios prácticos asociados a transformaciones en las trayectorias laborales de mujeres y hombres.

Palabras claves: Padres y madres profesionales; relaciones de género; distribución de tareas domésticas; parentalidad, trabajo doméstico.

\section{Introducción}

En el contexto de las transformaciones socioculturales y demográficas globales respecto de la conformación familiar y la conciliación con el mundo laboral, en Chile se han detectado cambios en los modos de organización tradicional del espacio doméstico. Es posible identificar respecto a la parentalidad, una tendencia a la ejecución compartida de múltiples tareas domésticas, indicando transformaciones en el quehacer práctico. No obstante, surge una pregunta medular: ¿han sido estas transformaciones suficientes para cuestionar el supuesto que responsabiliza a las mujeres por el espacio doméstico? A través

\section{(c) (7)}

Esta obra está sob licença Creative Commons. 
de esta investigación cualitativa, que recogió siete testimonios de mujeres y cinco de hombres, sostenemos que aun relevando las nuevas prácticas que han fisurado aspectos de la distribución tradicional de los roles domésticos, las familias encabezadas por personas con altas expectativas en su desarrollo personal y laboral están viviendo lenta e incipientemente el desgaste del hábito patriarcal de responsabilización femenina por el espacio doméstico y la práctica masculina de ignorar su responsabilidad en éste. De modo que se hablaría de cambios que reflejarían el hacer de hombres y mujeres, pero con continuidades medulares en su respectivo deber ser de cada género.

\section{Antecedentes: Trabajo productivo y relaciones de género en el ámbito doméstico}

Las relaciones de género en diferentes espacios microsociales (como los espacios de pareja y familiares) y macrosociales (como cultura y sociedad) se articulan vinculando indisociablemente las biografías de mujeres y hombres y los elementos contextuales en que se producen (Martha NAVA, 201 1). Así, en las familias como núcleo primario de desarrollo y socialización (Patricia HERRERA, 2000) se forman y reproducen imágenes propias y ajenas, a la vez que se configuran roles como una adaptación personal de prácticas e imágenes generalizadas socialmente.

El trabajo remunerado aparece como un factor relevante en la configuración y transformación, de los roles de los miembros de las familias. En las últimas décadas, la progresiva participación de las mujeres en el mundo del trabajo (Catalina WAINERMAN, 2007; Brígida GARCÍA y Orlandina DE OLIVEIRA, 2007) evidencia trayectorias laborales femeninas que transitan desde el empleo no calificado y el 'segundo sueldo', hacia la valoración del trabajo como aspecto central, planificado, con mayores remuneraciones y profesionalizado (Lorena GODOY, Antonio STECHER y Ximena DÍAZ, 2005). Este fenómeno ha ocurrido simultáneamente con numerosos cambios en las relaciones laborales y productivas, como el auge de empleos flexibles (Rosalba TODARO y Sonia YÁÑEZ, 2004) y atípicos (OIT/ PNUD, 2009).

Los cambios productivos mencionados van acompañados de transiciones demográficas y socioculturales que contribuyeron a la diversificación de los roles femeninos y los significados de la femineidad: la disminución de la natalidad; el aumento de emparejamientos tardíos; y, sobre todo, el incremento en los niveles de instrucción formal femenino (Marina ARIZA y Orlandina DE OLIVEIRA, 2001; WAINERMAN, 2007; Ximena VALDÉS, 2009). Asimismo, se advierte la incidencia de estos cambios en un fuerte cuestionamiento al modelo tradicional de paternidad, y consecuentemente la erosión de la imagen de autoridad paterna (Norma FULLER, 2005; VALDÉS, 2009).

El impacto de estas transformaciones estructurales ha relevado cambios en la configuración de roles de género en familias de diferentes contextos anglosajones (Katherine MARSHALL, 2006; He-Kang KIM, 2009) y latinoamericanos (GARCÍA y DE OLIVEIRA, 2007; WAINERMAN, 2007) vinculados a una mayor incorporación masculina en tareas del hogar. En el caso de Chile, las transformaciones están contenidas en el ámbito de la parentalidad, especialmente, en el creciente involucramiento afectivo y mayor participación paterna en tareas de crianza (Teresa VALDÉS y José OLAVARRÍA, 1997; Ximena VALDÉS y Teresa VALDÉS, 2005; FULLER, 2005; Macarena MARTÍNEZ, 2006; VALDÉS, 2009). Además, mayores niveles educacionales en la pareja redundarían en aportes económicos similares, permitiendo no solo una mayor valoración del trabajo productivo femenino, sino sustentar discursos equilibrados sobre la distribución de labores domésticas - aunque no se reflejen en las prácticas (María Cristina ARANHA y Arlene MARTíNEZ, 2012). 
Aun cuando sostenemos que las mujeres han ubicado sus proyectos individuales y de desarrollo laboral en un lugar central, ello no implica la pérdida de protagonismo del mundo reproductivo en sus rutinas y proyecciones, de modo que "el trabajo para las mujeres no reemplaza ni se opone al espacio familiar, sino que permanece articulado a éste. De allí la denominada doble adscripción identitaria de las mujeres" (GODOY, STECHER y DÍAZ, 2005 , p. 58). La relación entre trabajo y espacio doméstico muestra una permanente tensión que obliga a las mujeres a articular tiempos productivos y reproductivos para alcanzar una paradójica 'completitud'. Estas exigencias conllevan desventajas públicas, como la dificultad de acceder a posiciones de mayor prestigio, la reducción de jornadas laborales por la llegada de los(as) hijos(as) o la persistencia de brechas salariales entre hombres y mujeres, mayor aún en profesionales (FUNDACIÓN SOL, 2014), evidenciando desigualdades y discriminaciones laborales fuertemente enraizadas y de lenta erosión.

En el contexto europeo, Dominique Méda (2002) calificó este fenómeno como la persistencia de 'una sociedad inadaptada' frente a los cambios culturales y sociodemográficos, puesto que ni familias, ni empresas, ni Estado se han transformado lo suficiente para apoyar "la llegada masiva y duradera de las mujeres al mercado del trabajo" (MÉDA, 2002, p. 31). Ejemplo de ello es el alcance de las políticas públicas de conciliación, las que en Chile se han caracterizado por ser más bien maternalistas y orientadas a promover un rol subsidiario a la población vulnerable, más que a la corresponsabilidad (Merike BLOFIELD y Juliana MARTíNEZ, 2014).

Si bien las transformaciones culturales y prácticas han contribuido a equilibrar arreglos extremadamente inequitativos de antaño, éstas no han sido suficientes para cuestionar el fundamento de la desigualdad entre los géneros. A pesar del aumento de la participación masculina en labores reproductivas, se observa que las mujeres siguen asumiendo el núcleo fuerte de las tareas domésticas y los llamados 'trabajos sucios' (MÉDA, 2002; KIM, 2009; GARCÍA y DE OLIVEIRA, 2007). En Chile, aun cuando se develan tendencias que cuestionan los modelos tradicionales de paternidad y reivindican una participación más activa y afectiva en la crianza (Gonzalo GALLARDO, Esteban GÓMEZ, Magdalena MUÑOZ y Nicolás SUÁREZ, 2006), se advierte que estas prácticas, "no llegan al punto de cuestionar el supuesto tácito que el cuidado cotidiano de los(as) hijos(as) y de los asuntos domésticos sigue siendo una responsabilidad principalmente de las mujeres" (GODOY; STECHER y DÍAZ, 2005, p. 55). Así, cambia la asignación de roles domésticos, pero sin sustraer de las mujeres el peso de asegurar la reproducción doméstica. De manera que el conjunto sedimentado de representaciones semánticas y simbólicas adosadas a los cuerpos como 'hábitos sexualizados' (Pierre BOURDIEU, 2000) siguen asignando a lo femenino la responsabilización casi completa del espacio doméstico como actitud 'natural' o 'normal' (BOURDIEU, 2000).

En esta línea, Wainerman (2007) sostiene que además de la persistencia de tareas domésticas abiertamente reconocidas como 'femeninas' - rutinarias - y 'masculinas' esporádicas -, se distingue entre la responsabilización por una actividad reproductiva y la mera ejecución de ésta.

Las transformaciones vinculadas a la erosión del modelo paternal autoritario y el empoderamiento de todos sus integrantes como sujetos de derecho, son características de la familia actual. Sin embargo, el aparente equilibrio en la autoridad de padres y madres no necesariamente se traduce en una relación democrática respecto a la distribución de tareas domésticas, pues las mujeres permanecen tensionadas por el compromiso de responder a diversos roles, manteniendo una participación activa como madres. Según Cristina Carrasco (2014) en relación a los trabajos de cuidado, las mujeres tienden a dedicar más tiempo a la conciliación, salvo en casos excepcionales. En contraposición, los hombres logran 'liberarse' de estas responsabilidades, facilitando así su inserción y desarrollo en el 
mundo público. Por lo tanto, persiste el debate frente a la necesidad que el cuidado deje de ser un tema privado y de mujeres.

De ese modo, se habla de cambios experimentados en las familias, no así de la corresponsabilidad efectiva. En este sentido, la progresión de las mujeres en sus carreras profesionales y la ocupación de puestos de prestigio, responderían eminentemente a un esfuerzo personal, y con ello, familiar (José OLAVARRÍA, 2005). Más aún, teniendo en cuenta el tímido rol de protección social que juegan otros agentes como las empresas y el Estado (MÉDA, 2002; Ana María GOLDANI, 2002; Eduardo CAMAÑO, 2009), particularmente, las políticas públicas que incentivan débilmente la corresponsabilidad en Chile (BLOFIELD Y MARTÍNEZ, 2014).

\section{Metodología}

\begin{tabular}{|c|c|c|c|c|c|}
\hline $\begin{array}{l}\text { Identificación } \\
\text { (sexo y edad) }\end{array}$ & Profesión & $\begin{array}{l}\text { Nivel } \\
\text { estudios }\end{array}$ & $\begin{array}{c}\text { Tipo jornada } \\
\text { Iaboral } \\
\text { (completa: } \\
\text { 8h diarias) }\end{array}$ & $\begin{array}{c}\text { Tipo } \\
\text { jornada } \\
\text { laboral } \\
\text { pareja }\end{array}$ & $\begin{array}{l}\text { Hijos(as) } \\
\text { (sexo y edad) }\end{array}$ \\
\hline $\begin{array}{c}\text { Beatriz } \\
\text { (mujer, 31) }\end{array}$ & Abogada & Doctoranda & Completa & Completa & $\begin{array}{l}\text { - Niño (2) } \\
- \text { Niña (7) }\end{array}$ \\
\hline $\begin{array}{c}\text { Paula } \\
\text { (mujer, 29) }\end{array}$ & Abogada & Universitaria & Media & $\begin{array}{l}\text { Trabajo por } \\
\text { tumos fuera } \\
\text { de la ciudad }\end{array}$ & $\begin{array}{l}\text { - Niña (1) } \\
\text { - Niña (1 mes) }\end{array}$ \\
\hline $\begin{array}{c}\text { Tamara } \\
\text { (mujer, 34) }\end{array}$ & $\begin{array}{c}\text { Abogada } \\
\text { (docente universitaria) }\end{array}$ & Magister & Completa & Completa & - Niña (2) \\
\hline $\begin{array}{c}\text { Helena } \\
\text { (mujer, 30) }\end{array}$ & Trabajadora Social & Universitaria & Completa & Completa & $\begin{array}{l}\text { - Niña (3) } \\
\text { - Embarazo } \\
\text { (3 meses) }\end{array}$ \\
\hline $\begin{array}{c}\text { Javier } \\
\text { (hombre, 44) }\end{array}$ & $\begin{array}{l}\text { Ingeniero c. Industrial } \\
\text { (docente educación } \\
\text { superior) }\end{array}$ & Magister & Completa & Completa & $\begin{array}{l}- \text { Niña }(17) \\
- \text { Niño }(13)\end{array}$ \\
\hline $\begin{array}{c}\text { Graciela } \\
\text { (mujer, 29) }\end{array}$ & Abogada & Universitaria & Media & Completa & $\begin{array}{l}- \text { Niño (6) } \\
\text { - Niña (2) }\end{array}$ \\
\hline $\begin{array}{c}\text { Bemardo } \\
\text { (hombre, 30) }\end{array}$ & Ingeniero c. Indastrial & Universitario & Completa & Completa & - Niño (1) \\
\hline $\begin{array}{c}\text { Carlos } \\
\text { (bombre, 46) }\end{array}$ & $\begin{array}{l}\text { Kinesiōlogo } \\
\text { (docente universitario) }\end{array}$ & Doctorando & Completa & Completa & $\begin{array}{l}\text { - Niño }(10) \\
- \text { Niña }(10) \\
- \text { Niño }(2)\end{array}$ \\
\hline $\begin{array}{l}\text { Christopher } \\
\text { (hombre, 40) }\end{array}$ & $\begin{array}{c}\text { Kinesiólogo } \\
\text { (docente universitario) }\end{array}$ & Doctorando & Media & Media & $\begin{array}{l}- \text { Niño }(10) \\
- \text { Niña }(7)\end{array}$ \\
\hline $\begin{array}{c}\text { Patricia } \\
\text { (mujer, 46) }\end{array}$ & Educadora Diferencial & Magister & Completa & $\begin{array}{l}\text { Trabajo por } \\
\text { tumos fuera } \\
\text { de la ciudad }\end{array}$ & $\begin{array}{l}\text { - Mujer (21) } \\
\text { - Mujer (18) } \\
\text { - Niña (12) } \\
\text { - Niña (5) } \\
\end{array}$ \\
\hline $\begin{array}{c}\text { Gabriel } \\
\text { (hombre, 45) }\end{array}$ & Ingeniero Forestal & Magister & Completa & Completa & $\begin{array}{l}\text { - Niña (12) } \\
\text { - Niño (8) } \\
\text { - Niño (6) }\end{array}$ \\
\hline $\begin{array}{c}\text { Maria } \\
\text { (mujer, 35) }\end{array}$ & Educadora Diferencial & Universitaria & Completa & Completa & $\begin{array}{l}\text { - Niño (12) } \\
\text { - Niña (10) } \\
\text { - Niño (6) } \\
\text { - Niño (3) }\end{array}$ \\
\hline
\end{tabular}

Este estudio se sitúa desde un enfoque cualitativo e interpretativo (Samuel TAYLOR y Robert BOGDAN, 1996; Ruth VIEYTES, 2004). Se realizaron entrevistas semiestructuradas (Roberto HERNÁNDEZ SAMPIERI, Carlos FERNÁNDEZ-COLLADO y Pilar BAPTISTA, 2006) a siete mujeres y

4 Revista Estudos Feministas, Florianópolis, 26(2): e42931 
cinco hombres habitantes del Concepción urbano, profesionales (formación universitaria y laboralmente activos), con parejas (heterosexuales) que cumplieran la misma condición y que se identificaran como pertenecientes a la clase media. Se analizaron las entrevistas a través del método de análisis sociológico del discurso (Jorge RUIZ, 2009).

\section{Resultados: Relaciones de género y organización doméstica tensionadas}

En tanto que profesionales, el desarrollo intelectual y el mundo laboral se sitúan en el centro de sus proyectos de vida como espacios de sociabilidad que construyen y potencian aspectos subjetivos fuera de lo doméstico. Sin embargo, la distribución del tiempo laboral, personal y familiar muchas veces resulta en tensiones propias de la indisolubilidad de la relación entre lo público y lo privado, resolviéndose, en algunos casos, mediante prácticas ajustadas a la distribución tradicional de roles, y en otros, a través de prácticas más novedosas.

\section{Decisiones mayores y decisiones menores: de lo compartido a lo prioritariamente femenino}

La toma de decisiones emerge como un ámbito principal, y habitualmente está mediada por la negociación, en la cual se identifican dos ejes: las 'decisiones de área femenina/área masculina' y las 'decisiones mayores/menores'. En algunos testimonios, las 'áreas de dominio femenino' son asociadas a aquellas tradicionalmente de mayor competencia de las mujeres, por ejemplo, la decoración o amueblamiento de la casa. Los hombres declaran aquellas áreas vinculadas a lo normativamente masculino, por ejemplo, encargarse de trámites para comprar automóvil familiar.

La expectativa suele ser que estos asuntos sean resueltos por alguno de los integrantes de la pareja, sin necesariamente contar con la participación de la contraparte. Así lo comenta Patricia, cuyo testimonio relevó persistentemente una participación doméstica menos activa de su pareja, asociada fundamentalmente a sus largas jornadas laborales y los trabajos temporales fuera de la ciudad: "Todas esas cosas como domésticas, por decirlo así, yo las decido. O de qué color va a ser esa muralla, las cortinas van a ser de otro... esas, las decido yo y no le pregunto a nadie" (Patricia).

Las decisiones mayores son aquellas subrayadas como importantes; consecuentemente, consideradas como responsabilidad común y negociadas. Paula sostiene uno de los discursos más frecuentes: "Lo conversamos. Lo conversamos, vemos los pros y los contras, las ventajas y las desventajas, y ahí lo decidimos". Aquellas decisiones vinculadas al bienestar de los(as) hijos(as) o que conllevan importantes gastos de dinero serían consideradas 'mayores', como las decisiones de escolarizar, cambiar de colegio o comprar una casa. En estos casos, la negociación es fundamental, más aún cuando hay hijos(as) mayores, cuya participación en las decisiones suele estar legitimada, en concordancia con un progresivo empoderamiento infantil y adolescente. María, que tiene hijas sobre los diez años, declara: "Cuando hay decisiones respecto a las chiquillas [hijas] también les preguntamos a ellas" (María). Sin embargo, no todas aquellas decisiones relevantes y no rutinarias son responsabilidad común. Asimismo, aspectos como la brecha salarial entre los miembros de la pareja no tienden juzgarse como evidentes y se descartan como aspectos relevantes para la toma de decisiones.

Aquellas decisiones aparentemente menos relevantes, que son tomadas cotidianamente, se consideran como 'menores'. Un ejemplo de éstas sería determinar el 
menú de ese día o quién limpiará, es decir, son asuntos de reproducción doméstica. En este caso, a pesar de que Javier y su pareja poseen jornadas de trabajo similares en extensión, él reconoce que su esposa se encarga de las pautas 'menores':

Ella primero ve qué se va a cocinar, sí se va a cocinar, qué si cocina la señora que nos ayuda o si cocina ella, y si no va a cocinar. Si va a comprar algo para llevar a la casa o me llama a mí [...] pero, esas decisiones las toma ella, yo no, ahí no me meto (Javier).

En estos casos, una distinción sexualizada en la disposición que hombres y mujeres asumen frente a determinadas decisiones se revela con fuerza, de modo que la participación en la toma de decisiones o la validez de los argumentos negociados dependería principalmente del rol genérico que se desempeña, más allá de factores como el sueldo o la extensión de las jornadas laborales. Las decisiones menores se vinculan generalmente a las mujeres, considerando que implican resolver tareas rutinarias familiares, especialmente aquellas de 'auto-reproducción doméstica' y 'reproducción generacional' (OLAVARRÍA, 2005). Aun así, que sean las mujeres quienes se encargan de tomar estas decisiones no compromete que ellas las ejecuten, pero sí su supervisión.

Uno de los casos 'rupturistas' es el de Bernardo, quien declara su interés por asumir los trabajos de cuidado en corresponsabilidad. Él considera que la negociación permanente, tanto de decisiones mayores como de tareas rutinarias, no necesariamente es el mecanismo que construye la corresponsabilidad, dado que compartir el interés por desarrollar cualquier actividad doméstica habilitaría a ambos miembros para decidir, sin necesariamente consultar a la contraparte.

No existe una, una regla, así como ya: los días lunes yo me encargo, los días martes... no, sino es como bien aleatorio de acuerdo a quién está primero en la casa, quién quiere cocinar algo, quién se hace cargo de la cocina, mientras la otra persona ve otra cosa de la casa... no, no podría definir [...]. Pero sí que ambos lo hacemos (Bernardo).

En este sentido, cuando se trata de un tipo de organización que tiende a la corresponsabilidad, podríamos suponer que la división sexualizada de las 'tareas menores' se desdibujaría, asumiendo una atención indistinta como ámbitos de interés común.

\section{Tensiones en la vida reproductiva: persistencia de la distinción responsabilización- ejecución}

Debido a las largas jornadas de trabajo remunerado, las tareas reproductivas de mayor tensión - por frecuencia y demanda de tiempo -, son las vinculadas al cuidado de hijos(as). A diferencia de otros contextos, como el argentino, en que las tareas de cuidado suelen ser desempeñadas eminentemente por los progenitores (WAINERMAN, 2007), en el caso de Chile éstas son realizadas con gran frecuencia por colaboradoras domésticas u otras mujeres de la familia. Siendo un fenómeno que se inserta en un entorno que insiste en feminizar las labores de cuidado y fomenta escasamente la conciliación y corresponsabilidad, por consiguiente, las familias son obligadas a desplegar soluciones privadas para un problema público y masivo.

La externalización de la ejecución de tareas reproductivas a terceras personas femeninas aparece en todas las narraciones, colaborando en al menos algún período extenso de la trayectoria familiar. Ocho casos cuentan con el apoyo de una empleada doméstica, considerándolas un agente que descomprime la tensión - por trabajar; ejecutar labores domésticas; en algunos casos estudiar; y también criar - al ocuparse del cuidado personal de hijos(as), en su mayoría, menores de diez años. En Chile, la figura de la 
'empleada doméstica' no es equivalente a la de 'niñera', pues las primeras deben también encargarse de labores complementarias - preparación de comidas y limpieza -, aunque, muchas veces son supeditadas a otras tareas prioritarias. Para Carlos, el rol de la empleada doméstica es fundamental, y dada la extensión de las jornadas laborales de él y su pareja, constituye la estrategia más adecuada para el cuidado de su hijo menor de tres años:

Ella [empleada doméstica] nos dice o hay algún problema, que nuestro hijo se portó mal o está medio inquieto, que deje todo de lado y se preocupe de él. Esa es un poco nuestra prioridad. O sea, si no hay almuerzo o la casa no está aseada, es secundario (Carlos).

Para Christopher, recurrir a la colaboración de familiares, especialmente abuelas, es una estrategia usual de externalización de cuidados. En este caso, el rol que desempeña la abuela compensa la ausencia de otros agentes de colaboración doméstica: “...tenemos muy buena relación con mis suegros, yo, ningún problema, mi suegra viene, se queda con ellos, [...] tres días y los otros dos días viene la nana que los cuida" (Christopher).

Dada la carencia de políticas públicas de conciliación, la escolarización de los(as) hijos(as) emerge como otra estrategia para externalizar labores de cuidado que permite garantizar bienestar físico y emocional de los(as) hijos(as), sin alterar las jornadas laborales de la pareja. María expresa las aprehensiones de incorporar de terceros/as al espacio doméstico: "tomé miedo a tomar una persona, [... entonces todo el año pasado estuvieron en el jardín en jornada extendida".

La presencia de empleadas domésticas es considerada un elemento de continuidad dentro de la distribución tradicional y sexualizada de los roles de género. Es un hecho que la realización de las labores domésticas sigue estando adscrita a una figura femenina sin aparentes cuestionamientos, fortaleciendo la preconcepción que son las mujeres quienes están más familiarizadas con el cuidado y la vida doméstica, a ojos de los padres, madres y niños(as) atendidos(as) (VALDÉS, 2009). Asimismo, contar con apoyo doméstico no implica que las mujeres no realicen actividades domésticas - más aún cuando se tiende a establecer una relación laboral más cercana entre mujeres -, delegando aquello que ellas no pueden realizar personalmente. En varios casos, los hombres tienden a hablar de una 'automarginación' frente a decisiones menores y cotidianas, siendo aparentemente quienes menos tiempo y energía invierten en resolver tareas domésticas en razón de sus hábitos y situación laboral (OLAVARRÍA, 2005). Como consecuencia, las mujeres, suelen asumir simultáneamente sus funciones laborales y ejercer el rol protagónico en el espacio doméstico (FULLER, 2005).

No obstante, hay casos como el de Carlos, quien posee extensas jornadas laborales, y muestra responsabilización masculina ocasional:

Mi señora se encarga de eso... ella le deja... le hace [a la empleada doméstica] un check list de las cosas, ella se encarga de eso. Ella [su pareja] le deja todo ordenadito, armado, las comidas, las cosas... yo lo que hago de repente en el día es llamarla, para saber si hay algún problema, si necesita algo... pero, más como... abastecedor, que instrucciones (Carlos).

Mientras tanto, en rutinas como la de Bernardo, se habla de una participación masculina activa aun contando con empleada doméstica, dado que él procura tener un rol protagónico en la planificación e instrucción para el funcionamiento de la casa:

Yo paso más tiempo en la... en la casa, tengo más movilidad... podría considerarse que yo doy un poco esos, lineamientos. Pero, yo creo que tiene que ver nada más que por un tema de... de los tiempos que tenemos. A mí la pega independiente me permite 
más moverme y estoy ahí en la casa, harto, [...] y ahí es como... vamos dando las indicaciones (Bernardo).

Este caso muestra a un hombre de una generación joven con un empleo con flexibilidad horaria, por lo que dispone de más tiempo para participar en el ámbito reproductivo. Se observa que esta modalidad laboral contribuye a incentivar un mayor involucramiento masculino en el espacio doméstico.

La externalización de las labores de cuidado es un requerimiento derivado de la ausencia parental, por lo tanto, luego de las jornadas laborales, los adultos deben asumir las tareas domésticas no resueltas por agentes externos, siendo un espacio donde comúnmente se evidencian desequilibrios. Allí, tanto la responsabilización como la ejecución de las tareas domésticas son asumidas por el grupo familiar. En varios casos, las mujeres retoman una atención indistinta por el cuidado de los(as) hijos(as) y el mantenimiento del hogar - alimentar a los(as) hijos(as) y otras tareas como la limpieza doméstica. Mientras que, desde la experiencia masculina, se habla de una suerte de ejecución compartida de funciones, fundamentada en su disposición activa frente a ciertas tareas, como cocinar, realizar actividades lúdicas, de alimentación e higiene de los(as) hijos(as).

Gabriel, 45 años y tres hijos(as), da cuenta de esta forma de división de tareas, asumiendo que la distribución de roles se trata de una cuestión de 'rapidez y eficiencia', más que de una disposición diferenciada frente a tareas de limpieza o, abiertamente, atributos sexualizados: "Cuando yo estoy en la casa, yo me preocupo de la comida. [...] el aseo del baño, el lavado de la ropa, hacer las piezas, $A$. [su pareja] lidera ese trabajo. Ella es mucho más organizada, más rápida, más eficiente en eso..." (Gabriel).

En el caso de Graciela, dos hijos(as) y un trabajo de medio tiempo, la distribución de tareas con su pareja, luego de la jornada de laboral, se asemeja a lo comentado anteriormente. Sin embargo, las funciones asumidas por su esposo son bastante valoradas, aunque consideradas no 'expertas' en su ejecución, denotando diferentes estándares de rigurosidad para una misma tarea:

Cuando llega en la tarde el $N$. [pareja], no sé poh, si yo no... no he preparado algo, él se va a la cocina, - claro que deja el desastre en la cocina -, pero lo hace [...] yo les estoy ordenando las camas, él viene a hacer las leches y ese es como el proceso con los niños (Graciela).

Es importante distinguir que esta 'distribución equitativa' de tareas domésticas es limitada, si consideramos que las funciones ejecutadas preferentemente por los hombres están vinculadas a la crianza y a la alimentación de los hijos(as), es decir, a aquellas de 'reproducción generacional' por sobre las de 'auto-reproducción familiar'. Curiosamente, son aquellas que conllevan un sentido de reconocimiento o retribución afectiva. Por ejemplo, vestir o bañar a los(as) hijos(as) implica contacto afectivo con ellos(as); cocinar para el grupo familiar usualmente es gratificante. Patricia, quien cuenta con la participación de su pareja en este tipo de tareas de manera esporádica, comenta que: "Él coopera en preparar algo rico de comida, no sé poh, si estamos en la casa él prepara algo rico, los asados [ríe] son salvadores". En cambio, la mayoría de las tareas de auto-reproducción familiar no arrastrarían retribuciones explícitas ni reconocimientos.

Patricia también es un caso en que el rol de sus hijas adolescentes es fundamental para organizar su extenuante rutina. Puesto que sus hijas tienen diferencias de edad considerables, las mayores colaborarían con el cuidado de las menores, comúnmente como consecuencia de la presión parental, incluso como 'obligación'. En este caso, las funciones de sus hijas son consideradas como una forma de cooperación 'inscrita' en la crianza:

8 Revista Estudos Feministas, Florianópolis, 26(2): e42931 
De repente la más grande dice, 'ya mamá yo la voy a acostar' [a la hermana pequeña], y la va a acostar y la arropa [...] O, si están en la casa, a veces la van a buscar ellas al jardín y se la llevan a la casa. Asumen sí, asumen tareas, hartas. Pero, a veces obligadas, un poco (Patricia).

Al tratarse de hombres y mujeres que comprometen gran parte de su tiempo a actividades profesionales, la organización de las tareas domésticas y especialmente el cuidado de los (as) hijos (as) está supeditado al apoyo de asistencia doméstica o familiar. Durante sus actividades laborales, las empleadas domésticas contribuyen a distender las complicaciones ocasionadas por la falta de tiempo de los padres para ocuparse de labores reproductivas. Asimismo, esta relación sería un rasgo de continuidad del vínculo esperado entre mujeres y el cuidado doméstico y reproductivo, dado que el papel desempeñado por los hombres es visto comúnmente como un complemento. Por tanto, a pesar de no ejecutar el cuidado, las mujeres son quienes coordinan y supervisan a quien lo realiza.

\section{El arreglo de desperfectos domésticos y labores afines: responsabilización masculina en tareas no cotidianas}

Este ámbito constituye un área de responsabilización masculina por excelencia, en tanto hombres y mujeres mantienen la expectativa que los varones se encarguen. La literatura ha evidenciado que es habitual que los hombres se ocupen de estas funciones, siendo resueltas con más soltura y comodidad respecto de otras tareas domésticas (OLAVARRÍA, 2005).

Gabriel, ingeniero forestal, sostiene que son tareas satisfactorias de las que suele encargarse. Es necesario notar que el hecho de ser tareas de baja frecuencia podría influir en su percepción de satisfacción.

Tengo una colección de herramientas que es de harta utilidad para los quehaceres de la casa, en cuestiones básicas, las tratamos de resolver nosotros. La A. [su pareja] también. [...] no se queda sentada ella, pero... de alguna manera yo soy como el encargado de hacer la mantención, y me gusta (Gabriel).

Carlos, cuyo discurso representa continuidades, considera que este tipo de labores es una forma importante de participación y, de algún modo, compensaría la distribución dispar de las tareas domésticas:

Todo lo que sea de cosas de maestreo de la casa, las asumo yo. (...) un fin de semana si hay que arreglar algo, - yo le decía -, yo no voy a estar preocupado de lavar la loza, [...] entonces, ahí yo asumo roles de... de resolver problemas más complejos de la casa, mientras mi señora se encarga de mantención de la casa (Carlos).

Asimismo, se desprende de este relato la exacerbación de la división de tareas masculinas y femeninas (WAINERMAN, 2007) para no interferir en el área de dominio de cada quien, cuestión que reforzaría la idea del quehacer masculino como imprescindible, aunque sea ocasional.

La manera en que se resuelve materialmente ese tipo de tareas es diferente dependiendo de la complejidad del asunto. Si la tarea es 'sencilla', por ejemplo, arreglar un enchufe o llevar el automóvil al mecánico, generalmente los hombres tienden a ejecutarlo personalmente. Cuando se trata de desperfectos que superan sus habilidades, se tiende a externalizar su ejecución a través de otras figuras masculinas - un gasfíter o acudiendo a servicios técnicos. 
En casos como el de Tamara, la utilización de servicios externos para el arreglo de desperfectos depende principalmente de la voluntad o del tiempo que su pareja dispone para realizarlas. Tanto Tamara como su pareja se desempeñan como docentes universitarios y son simultáneamente estudiantes de un posgrado. Por lo tanto, el trabajo doméstico les representa una tercera jornada. Debido a lo extenuante de sus rutinas, muchas de sus tareas de auto-reproducción doméstica tienden a aplazarse, especialmente, las menos urgentes.

Le digo, - 'M. [pareja], se echó a perder tal cosa- 'si a los dos días la cuestión no está... no se arregló, le digo 'voy a llamar a un tipo' [...] hago el primer llamado al "macho alfa" [irónicamente] pero si el primer llamado al 'macho alfa'... hago el segundo y si el segundo llamado al 'macho alfa' no responde, se va a llamar a sustituto. En tercera instancia se llama a otra persona (Tamara).

Las expectativas de responsabilización por estas tareas parecen seguir siendo eminentemente masculinas. Sin embargo, al tratarse de requerimientos puntuales, su ejecución es con menos celeridad que las tareas reproductivas. Así, la externalización de este trabajo aparece como una alternativa común, al punto que la expectativa que sea 'el hombre de la casa' quien se encargue de estas tareas, podría estar redefiniéndose.

\section{Hacia la parentalidad compartida}

Existen antecedentes que permiten sostener que el ámbito de mayor involucramiento masculino ha sido la crianza (OLAVARRÍA, 2005; VALDÉS, 2009). Es usual que padres y madres compartan tareas reproductivas como bañar, alimentar o mudar a sus hijos(as). No obstante, de los discursos se desprende que la participación masculina en tareas domésticas vinculadas a la crianza no sólo no equipararía al trabajo realizado por las madres, sino seguiría basándose en la idea que ellas tienen mayor sensibilidad en el cuidado como una cuestión casi 'intuitiva'. La parentalidad podría presentarse como una actividad tremendamente colaborativa, aunque no completamente compartida. Así, en conjunto con el arreglo de desperfectos, este ámbito constituiría un espacio en el cual algunos hombres han podido desenvolverse activamente y acomodarse sin remover completamente su posición privilegiada.

Un aspecto práctico que media en la relación de padres y madres e hijos(as) es la extensión de las jornadas escolares y principalmente, laborales de los adultos. En algunos casos, las jornadas laborales femeninas son menos extensas que las masculinas, lo que favorecería la expectativa que se encarguen de retomar las funciones domésticas al llegar al hogar. Entonces, se configura un escenario en que ellas logran pasar más tiempo con sus hijos(as), evidenciando una mayor ejecución y responsabilización por las tareas reproductivas. Muchas veces, la participación de los padres está sujeta a las indicaciones femeninas. Así lo muestra Carlos, quien declara un rol menos propositivo al respecto:

Por ejemplo, dice [la pareja]: 'sabes que voy a hacer tal cosa, preocúpate tú darle la comida a F. [hijo]', ahí entonces me encargo yo. Pero ella sí, más dirige, [...] en esas cosas como más como relevantes, más importantes (Carlos).

En aspectos de la crianza vinculados a la formación de hábitos, principios, valores y límites, adquiere relevancia la negociación sobre su contenido y la forma de implementarlos. En la mayoría de los casos, existiría una preocupación expresa por discutir previamente en la pareja estos asuntos e implementar en alianza lo acordado. Así lo relata Helena, una mujer joven y trabajadora social del área educacional: "no le digo nada delante de la niña [hija] porque el tema de desautorizarnos delante de ella es terrible para la crianza posterior... y eso, lo tenemos clarito los dos..." (Helena). 
Cuando se trata de estructurar rutinas, poner límites y corregir a los hijos(as), se reconoce que la actitud con que padres y madres llevan a la práctica lo acordado es diferente, asimismo, lo es la imagen proyectada frente a sus hijos(as). En varios casos, las madres se consideran un referente más estricto y los padres uno más flexible. En esto incidiría la cantidad de horas que pasan los(as) hijo(as) con cada uno(a) de ellos, y el tipo de tareas de las cuales se encargan, considerando que las madres generalmente asumen actividades rutinarias, vistas como 'obligatorias' o no lúdicas. Ejemplo de ello es el testimonio de María, quien tiene cuatro hijos(as), “... de repente igual me dicen '(...) aquí hay una bruja icierto?', - me dicen - [ríe]. No sé poh, me... me agarran para el leseo de repente las chiquillas [sus hijas]".

Entrevistadas, y principalmente entrevistados, destacaron el rol participativo de los padres en actividades lúdicas, recreativas y de aprendizaje, en cuyos espacios se desarrollarían estrechos vínculos afectivos con sus hijos(as), estableciendo una distinción positiva respecto del trato lejano que recibieron de sus propios padres, como señala la literatura (OLAVARRÍA, 2005; VALDÉS 2009). El involucramiento paterno se caracterizaría por acompañarlos en los deberes escolares; jugar y enseñarles artes o deportes, destacándose su iniciativa por organizar actividades familiares al aire libre. En este ámbito, se manifiesta cercanía afectiva entre padres e hijos(as), revelando características de la imagen paterna actual entrelazadas al fenómeno de la erosión de la estricta autoridad del padre (VALDÉS, 2009). En cuanto a esto, Carlos señala: "En general, tratamos de hacer cosas en familia. Mi señora no adhiere mucho a la actividad física, por lo tanto... salidas en bicicleta, caminatas y cosas que nos gustan, normalmente lo hacen conmigo".

En concordancia con esta imagen paterna afectiva y lúdica, Helena expresa sobre la relación de su pareja e hija: "Es cercana, son bien cómplices... como que se miran y ríen solos... Yo creo que también tiene que ver con este gusto que comparten por el tema de la música" (Helena).

Sin embargo, estas representaciones paternas y maternas no serían estáticas. Los episodios de conflicto con los(as) hijo(as) emergen como un punto de inflexión, y en varios casos la severidad materna transitaría hacia la benevolencia, mientras que la flexibilidad paterna hacia la severidad, dada su 'capacidad de empoderamiento' más efectiva frente a los hijos(as) para corregir comportamientos. Lo que demostraría el atributo masculino de transitar por distintas 'versiones' masculinas sin dañar su prestigio (FULLER, 1997), en contraposición con las mujeres, quienes tenderían a ser deslegitimadas. En este sentido, podríamos plantear la persistencia de un modelo paternal tradicional en tensión con uno contemporáneo más flexible.

Así lo describe Graciela, pues aparentemente el hecho de pasar más tiempo con sus hijos(as), dada su media jornada laboral, produciría desgaste y rutinización de los mecanismos de control que ejerce frente a sus hijos e hijas. Por lo tanto, la imagen de su pareja, ausente la mayor parte del día, representaría un recurso más efectivo para la aplicación de reglas y el 'disciplinamiento', incluso a través de la violencia física.

$Y$ al $N$. [pareja] le tiene más miedo en ese sentido que a mí, así como que él dice algo y es... porque por lo normal yo soy... yo siempre lo reto todo el día [...] Pero cuando lo reta él, sabe que es por algo realmente importante. Claro... yo soy como la mala... constante, pero él es el malo de verdad (Graciela).

Para la mayoría de los(as) entrevistados(as), el método consistiría en evitar la desautorización y respaldar las indicaciones o reprimendas de alguno de los progenitores. En ese sentido, el respeto por las posturas consensuadas constituiría un pilar de la crianza, aportando a la formación de los(as) hijos(as) y como mecanismo que realza la alianza 
conyugal, evitando disputas que desestabilicen la solidez de la autoridad parental, especialmente cuando la fidelización de la relación con los(as) hijos(as) se acrecienta (VALDÉS, 2009) y ellos(as) son cada vez más conscientes de sus derechos.

\section{Participación masculina creciente acotada o a conveniencia en la vida reproductiva: una reedición del modelo tradicional}

El aumento de la participación de los hombres en tareas domésticas, sobre todo parentales, se ha manifestado. Sin embargo, además de las particularidades ya discutidas al respecto, es importante precisar otros elementos para considerar si aquellas transformaciones evidenciarían rupturas más profundas en el formato de distribución tradicional de roles domésticos.

Uno de los hallazgos significativos alude a que expresar mayor participación masculina en las tareas del hogar no necesariamente apuntaría a una distribución democrática de los roles domésticos, a la vez que seguiría primando la responsabilización femenina por este espacio. En lo práctico, varios casos mencionaron que la participación masculina frecuentemente se materializa una vez que su ejecución es sugerida o impulsada por las mujeres. Así, la 'sensación' de equilibrio en la distribución de tareas domésticas podría basarse en el hecho de compartir su ejecución en circunstancias que la responsabilización y la organización del espacio doméstico parece descansar en las mujeres. En relación a esto, Graciela, quien debe hacerse cargo del cuidado de sus hijos(as) rutinariamente en ausencia de su pareja, comenta: "así como una vez al mes digo: 'iPero es que no me ayudas en nada!', ya, y hace todo [su pareja]... entonces, yo sé que igual lo hace cuando yo de verdad estoy complicada, me ayuda" (Graciela).

En un sentido similar, el relato de Helena se refiere a cómo debe 'sugerir' a su pareja la participación en tareas poco reconocidas: "En la limpieza del baño, ponte tú. Le carga [a su pareja]. No le gusta. Pero yo digo, 'bueno, si usted ensució, usted limpia'. Regaña un rato, pero después lo hace igual..." (Helena).

Es frecuente en los testimonios el uso de las frases 'me ayuda', 'me colabora', o 'trato de 'ayudar' o 'colaborar', en el caso de los hombres. Así lo relataba Christopher, quien, en su testimonio, da cuenta de una participación activa en ciertas tareas de cuidado y autoreproducción doméstica, aunque, sin identificarlas como una responsabilidad propia: "yo trato de ayudar en lo más posible, pero [...] en lo que es planchado, una cosa es querer cooperarle y otra cosa es hacerlo bien..." (Christopher).

En estos casos, si bien se manifiesta disposición masculina a realizar tareas de autoreproducción familiar como cocinar, lavar la loza, hacer aseo, entre otras, su ejecución no necesariamente surgiría proactivamente, sino sujeta a la petición directa o delegación de funciones por sus parejas, percibiéndose como tareas específicas y acotadas. Esto pareciera reforzarse con otras ideas conservadoras de hombres y mujeres, como que la preocupación por la limpieza y el orden es un hábito 'propiamente' femenino o es considerado como un asunto menor. "Ella [su pareja] es más pendiente de los temas del aseo" (Javier).

Tamara, reconoce como motivo de significativo conflicto en la organización de las tareas domésticas, el interés desigual en su pareja por el orden y aseo: “...en el fondo su [de la pareja] umbral de soporte de... de 'chiquerismo' [desaseo] es mayor... y eso genera conflicto" (Tamara).

La argumentación naturalizada sobre la tendencia femenina a interesarse más por el orden y limpieza, tiende a traducirse a un rasgo esencial e irrenunciable. Desde esta perspectiva, pareciera que las mujeres sabrían manejar espontáneamente, cómo, cuándo y qué hacer en ese ámbito, mientras que en el caso de los hombres, esta relación sería 
forzosa y deficiente. Por lo tanto, la progresión en la participación masculina en el hogar estaría basada en una especie de 'tutelaje' femenino. Helena, de 30 años, reconoce un avance importante en la participación de su pareja en tareas domésticas como parte de un proceso orientado por ella, "... a veces yo simplemente no hacía de comer no más, entonces finalmente tuvo que ir aprendiendo y fue casi, tirarlo por la ventana." (Helena)

Sobre estas narraciones podemos sostener que persiste una representación femenina sobre sí mismas, inclinada al hábitus (BOURDIEU, 2000) de responsabilización de las tareas domésticas, mientras que en el caso de los hombres permanecería el hábitus de la comodidad relativa en base a la distribución tradicional de roles. La presión femenina sobre sus parejas para asumir y ejecutar responsabilidades no sería otra cosa sino un permanente esfuerzo por re-formar el hábito masculino del privilegio hacia un hábito guiado a la proactividad, un permanente 'orientar'.

Graciela no habla de esfuerzos por motivar a su pareja, pues se reconoce a sí misma heredera de un machismo 'irrevocable'. De ahí que su adecuación a la falta de participación masculina alcanza tales límites que no provocaría mayores conflictos, salvo en situaciones excepcionales de sobrecarga laboral, en que apela a un mayor involucramiento de su pareja, expresando una aceptación acrítica de los roles tradicionales de género.

Cuando no estoy complicada, es porque me gusta hacerlo, es como que dijera: 'me gusta tomar helado', entonces para que me va a él [su pareja] a comérmelo, si a mí me gusta comérmelo sola... a mí me gusta ordenar sola, porque me gusta saber dónde están las cosas, [...] yo siempre le he dicho a mi mamá: 'ah, es tu culpa', porque es como... criada machista... pero, ya: ¿qué voy a hacer? - decía, luego -. Ya soy así (Graciela).

En este caso, el desequilibrio en la distribución y responsabilización de las tareas domésticas es justificado a través de diversas razones, y a pesar de asumirse conscientemente el desequilibrio, no se declaran intenciones de superar la disparidad.

Desde otra perspectiva, como caso atípico, encontramos el testimonio de Bernardo, quien relata prácticas equilibradas en términos de ejecución y responsabilización doméstica. Al mismo tiempo, este joven relevó en su discurso la importancia de compartir labores, y de asumir roles más participativos en las decisiones menores, así como en la planificación del funcionamiento del hogar y la delegación de funciones a terceras personas, manifestando una postura expresa y crítica no sólo frente al patrón tradicional de asignaciones de género, sino también frente a formas de participación masculina más activas, aunque no equitativas.

Nunca me ha gustado mucho ser tan asistido, ya, y no me molesta asistir. Más bien me gusta, participar y cooperar, y más que colaborar, hacerse cargo de las cosas que pasan en los espacios. Así como que no es que voy a 'cooperar' o voy a 'colaborar', porque voy a lavar la loza, sino que, si ensuciamos la loza, hay que lavarla (Bernardo).

De esa manera, Bernardo plantea que la ejecución de ciertas tareas puntuales o esporádicas no debería presentarse como colaboración, sino como responsabilidad. De tal modo, la responsabilización debería asumirse como el fundamento de la ejecución de cualquier tarea doméstica.

Finalmente, es significativo relevar que en los discursos de las doce personas entrevistadas no se habló de nula ni escasa participación femenina en las labores domésticas, tanto en la ejecución como en la responsabilización. 


\section{Reflexiones finales}

El análisis presentado se basa en testimonios y valoraciones que hombres y mujeres realizan respecto a su experiencia. Dicho esto, es importante tener en cuenta que las reflexiones expuestas sólo reflejan lo que hombres y mujeres asumen sobre sus prácticas, y no necesariamente lo que ellos y ellas hacen.

La condición de padres y madres profesionales supone un interés central por el trabajo remunerado o por la continuidad de estudios, tanto desde una posición individual como familiar, donde la organización doméstica confronta los tiempos de ambas dimensiones. Por ello, las familias despliegan diversas dinámicas de organización del hogar, denotando cambios y continuidades en las maneras de establecer arreglos y articular las relaciones de género. Una de las estrategias más utilizadas es el apoyo de empleadas domésticas y familiares mujeres en quienes se externaliza la ejecución de las tareas y el cuidado de los(as) hijos(as), evidenciando la continuidad y extensión de la responsabilización femenina a terceras.

Los discursos sobre el aumento de participación de los hombres y otros integrantes de la familia denotan cambios, aun cuando éstos no excluyen continuidades en las dinámicas familiares. En muchos casos, se orientan a la ejecución de tareas domésticas puntuales u ocasionales (WAINERMAN, 2007), respecto de las cuales expresan mayor comodidad (OLAVARRÍA, 2005), como aquellas relativas a la reproducción generacional y a la crianza y cuidado de los(as) hijos(as), con quienes se vinculan afectivamente. Este es un hallazgo consistente con los antecedentes referidos a la erosión del modelo de paternidad tradicional, no obstante en la mayoría de los casos subyace la idea que las madres poseerían mayor sensibilidad para resolver el cuidado.

Sobre estos casos, podríamos plantear que la participación masculina no ignora los ámbitos de organización doméstica, pues como discurso común, la decisión de involucrarse en ciertas tareas habitualmente se relaciona con la delegación de funciones por parte de su pareja, siguiendo las indicaciones de ella respecto al estándar de orden y limpieza necesario para la familia. En estas ocasiones, una mayor participación masculina en labores de reproducción doméstica dependería de un mayor esfuerzo femenino por orientarlas. Vale mencionar que esta dinámica varía cuando se trata de resolver asuntos de mayor envergadura donde se emplearía la negociación, aun considerando en ocasiones argumentos definidos respecto a áreas de dominio esperadas para hombres y mujeres.

La sedimentación de la rutina marcada por un rol activo de las mujeres se arraiga en prácticas entrelazadas con elementos culturales. La necesidad de resolver rápidamente durante los días hábiles se toma como un argumento de peso para que las mujeres destinen una mayor cantidad de horas al trabajo doméstico, dada la creencia que son capaces de resolver múltiples propósitos en poco tiempo. Entonces, el hábito femenino de participar proactivamente en tareas domésticas podría relacionarse con una actitud pasiva de sus parejas. Es interesante notar que varios de los testimonios revisados, tanto de hombres como mujeres, consideran que sus arreglos domésticos son respuestas 'naturales' o 'espontáneas' ante la contingencia, sin reparar que esa aparente naturalidad podría esconder una distribución fundada en hábitos sexualizados y desigualdades de género.

Existen testimonios que declaran transformaciones en la organización del espacio doméstico. No obstante, dichas transformaciones se mantienen en el plano de la ejecución y de la resolución práctica, destacando la participación masculina respecto de generaciones anteriores y la incorporación de terceras personas para la ayuda doméstica - como práctica habitual en la clase media chilena -, con el objetivo de distender la sobrecarga de criar y trabajar dentro y fuera del hogar. Los cambios evidenciados no han 
sido suficientes para establecer la existencia de corresponsabilidad en las tareas domésticas, y tampoco en la crianza, salvo en el caso de uno de los entrevistados, cuyo relato manifestó expresamente la preocupación por el equilibrio en lo reproductivo. El hábitus feminizado de participación y responsabilización por lo doméstico y la crianza sigue, en líneas generales, en sintonía con un hábitus masculino de pasividad y participación esporádica, la que es condicionada tanto por la retribución afectiva como por el estímulo femenino.

En razón de lo anterior, persiste la expectativa que presiona a las mujeres a tener la iniciativa y guiar las tareas domésticas y de cuidado. Por lo tanto, los hallazgos presentados no ofrecerían en sí mismos argumentos suficientes para sostener que se ha revertido el modelo de organización tradicional en estas familias de profesionales, llegando a arreglos igualitarios o de corresponsabilidad - salvo en excepciones. No obstante, podríamos sostener que nos enfrentamos a un conjunto de familias que mencionan prácticas tendientes a cambios, que no necesariamente son etapas en el continuo hacia la corresponsabilidad, sino que más bien se derivan de los diversos arreglos negociados a partir de tensiones experimentadas por las exigencias principalmente laborales, las expectativas frente a la crianza y la falta de política pública orientada a la conciliación.

La excepción de uno de los casos en que se habló de una configuración familiar corresponsable requiere problematizarse incorporando dimensiones no sólo relacionales, sino que también estructurales, como el tipo de empleo de los integrantes de la pareja y la flexibilidad laboral como un aliciente. Mientras tanto, los otros casos reflejarían modos de organización del trabajo doméstico, cercanos a reediciones del modelo tradicional, más flexible en la práctica, pero que en esencia conservarían las expectativas de la división sexual del trabajo reproductivo, impidiendo la subversión de prácticas culturales medulares del desequilibrio: el hábito femenino del servicio versus el hábito masculino del privilegio.

\section{Referencias}

ARANHA, María Cristina y MARTíNEZ, Arlene. "Revendo estereótipos: o papel dos homens no trabalho doméstico". Revista Estudos Feministas, Florianópolis, v. 20, n. 1, p. 259-287. 2012.

ARIZA, Marina y DE OLIVEIRA, Orlandina. "Transiciones familiares y trayectorias laborales femeninas en el México urbano". In: GOMES, Cristina (Comp.). Procesos sociales, población femenina y familia. Alternativas teóricas y empíricas en las investigaciones sobre vida doméstica. México: FLACSO - Editorial Porrúa, 2001. p. 129-146.

BLOFIELD, Merike y MARTINEZ, Juliana. "Trabajo, familia y cambios en la política pública en América Latina: equidad, maternalismo y corresponsabilidad". Revista CEPAL, Santiago, n. 114, p.107-125. 2014.

BOURDIEU, Pierre. La dominación masculina. Barcelona: Editorial Anagrama S.A, Pedro de la Creu, 2000.

CAMAÑO, Eduardo. "Los efectos de la protección a la maternidad para la concreción de la igualdad de trato entre los hombres y las mujeres en el trabajo". Revista de Derecho Pontificia Universidad Católica de Valparaíso, Valparaíso, p. 185-214. 2009.

CARRASCO, Cristina. "La economía feminista: ruptura teórica y propuesta política". In: (Ed.). Con Voz Propia. Madrid: Ed. Viento Sur/ La Oveja Roja, 2014. p.25- 48.

GODOY, Lorena; STECHER, Antonio y DÍAZ, Ximena. "Significados del trabajo, identidad y ciudadanía. La experiencia de hombres y mujeres en un mercado laboral flexible". Cuaderno de Investigación, Santiago, Centro de Estudios de la Mujer, n. 3, p.55-62. 2005. 
FULLER, Norma. "Las identidades de género en el Perú del siglo XXI ¿Cambio o reciclaje?" In: VALDÉS, Teresa y VALDÉS Ximena (Eds.). Familia y vida privada: ¿Transformaciones, tensiones, resistencias y nuevos sentidos? Santiago: FLACSO, 2005. p. 107-132c.

FULLER, Norma. "Fronteras y retos: Varones de clase media del Perú". In: VALDÉS, Teresa y OLAVARRÍA, José (Eds.). Masculinidad/es, Poder y Crisis. Santiago: Ediciones de las mujeres, n. ${ }^{\circ}$ 24, FLACSO/Isis internacional, 1997. p. 139-152.

FULLER, Norma. Dilemas de la femineidad: mujeres de clase media en Perú. Lima: Fondo Editorial, Pontificia Universidad Católica del Perú, 1993.

FUNDACIÓN SOL. Mujer en el mundo del trabajo. Desafíos para el siglo XXI. Santiago, 2014. GOLDANI, Ana Maria. "Família, gênero e políticas: famílias brasileiras nos anos 90 e seus desafios como fator de proteção". Revista Brasileira de Estudos de População, Rio de Janeiro, v. 19, n. 1, p. 29-50. 2002.

GARCÍA, Brígida y DE OLIVEIRA, Orlandina. "Trabajo extradoméstico y relaciones de género: una nueva mirada". En: GUTIÉRREZ, María Alicia. Género y trabajo: rupturas y continuidades. Desafíos para la investigación política. Buenos Aires: CLACSO, 2007. p. 49-87.

GALLARDO, Gonzalo; GÓMEZ, Esteban.; MUÑOZ, Magdalena y SUÁREZ, Nicolás. "Paternidad: Representaciones Sociales en Jóvenes Varones Heterosexuales Universitarios sin Hijos". Psykhe, Santiago, v. 15, p.105-116. 2006.

HERNÁNDEZ SAMPIERI, Roberto; FERNÁNDEZ-COLLADO, Carlos y BAPTISTA, Pilar. Metodología de la investigación. Cuarta Edición. México: McGraw-Hill/Interamericana Editores, 2006.

HERRERA Patricia. "Rol de género y funcionamiento familiar". Revista Cubana Medicina General Integral, La Habana, v. 16, n.6, p. 568-573. 2000.

$\mathrm{KIM}$, Hee-Kang. "Analyzing the gender division of labor: The cases of the United States and South Korea". Asian Perspective, Changwon, South Korea, v. 33, n. 2, p. 181-229. 2009.

MARSHALL, Katherine. "Converging gender roles". Statistics Canada, 75-001, p.1-13. 2006.

MARTíNEZ, Macarena. Construcción simbólica de la figura paterna a través de dos generaciones de varones heterosexuales de clase media habitantes de la ciudad de Concepción. 2006. Tesis (Magíster) - Universidad de Chile, Santiago, Chile.

MÉDA, Dominique. El tiempo de las mujeres. Conciliación entre vida familiar y profesional de hombres y mujeres. Madrid: Narcea Ediciones, 2002.

NAVA, Martha. "Autorrealización y vida en pareja en estudiantes universitarios". Enseñanza en Investigación en Psicología, México, v. 16, p. 323-338. 2011.

RAMOS, Miguel Ángel. "La paternidad y el mundo de los afectos". FEM, Publicación Feminista Mensual, México D.F., año 25, n. 219. 2001.

OIT/PNUD. Trabajo y Familia: Hacia Nuevas Formas de Conciliación con Corresponsabilidad Social. Santiago: OIT-PNUD, 2009.

OLAVARRÍA, José. "¿Dónde está el nuevo padre? Trabajo doméstico: de la retórica a la práctica". In: VALDÉS, Ximena y VALDÉS, Teresa (Eds.). ¿Transformaciones, tensiones resistencias y nuevos sentidos? Santiago de Chile: FLACSO, 2005. p. 215-274.

RUIZ, Jorge. "Análisis sociológico del discurso: métodos y lógicas". Forum Qualitative Social Research, Berlín, v. 10, n. 2, art. 26. 2009.

TAYLOR, Samuel James y BOGDAN, Robert. Introducción a los Métodos Cualitativos de Investigación: la búsqueda de significados. Barcelona: Ediciones PAIDOS, 1996.

TODARO, Rosalba y YÁÑEZ, Sonia. El trabajo se transforma: Relaciones de producción y Relaciones de género. Santiago: Centro de Estudios de la mujer, 2004.

VALDÉS, Ximena. "El lugar que habita el padre en Chile contemporáneo: Estudio de las representaciones sobre la paternidad en distintos grupos sociales". Revista POLIS, Santiago de Chile, v. 8, n.23, p. 385-410. 2009.

16 Revista Estudos Feministas, Florianópolis, 26(2): e42931 
VALDÉS, Teresa y OLAVARRÍA, José. Masculinidad/es: Poder y crisis. Santiago: Isis Internacional, 1997.

VALDÉS, Ximena y VALDÉS, Teresa (Eds.). Familia y vida privada. ¿Transformaciones, tensiones, resistencias y nuevos sentidos? Santiago: FLACSO, 2005.

VIEYTES, Ruth. Metodología de la investigación en organizaciones, mercado y sociedad: epistemología y técnicas. Buenos Aires: De las ciencias, 2004.

WAINERMAN, Catalina. "Conyugalidad y paternidad ¿Una revolución estancada?" En publicación: Género, familias y trabajo: rupturas y continuidades. Desafíos para la investigación política. Buenos Aires: CLACSO, 2007.

[Recebido em 08/02/2016,

reapresentado em $23 / 03 / 2017$

e aprovado em 04/12/2017]

Gender relations and organization in couples who work outside home: execution $v / s$ responsability

Abstract: This paper aims to show the results of a qualitative empirical research that addresses the gender relations and the domestic arrangements of households formed bycouples who work outside home from Great Concepción, Chile.

Biographical aspects, professional expectations and labour development are analysed against theoretical-contextual elements throughout the study, in order to characterise the domestic dynamics and routines displayed among family members. From the accounts, it is possible to identify some findings that allow sustaining the persistency of elements ascribed to the traditionalpatriarchal model of domestic-role distribution, as well as some changes in the practices, linked to female and male labour trajectories transformations.

Keywords: Professional mothers and fathers; gender relations; domestic chores distribution; parenting; household labour.

Relações de gênero e organização em casais que trabalham fora de casa: execução vs. responsabilidade

Resumo: Este artigo apresenta os resultados de uma investigação empírica qualitativa, que aborda as relações de gênero e as adaptações domésticas configuradas em lares de casais que trabalham na região da Grande Concepción urbana, Chile. Durante este estudo problematizaram-se elementos biográficos, expectativas profissionais e desenvolvimento laboral, com elementos teóricos-contextuais, de modo a caracterizar como se desenvolvem as dinâmicas e as rotinas domésticas entre os integrantes destas famílias. A partir dos testemunhos, identificamse descobertas que permitem sustentar a persistência de elementos adscritos ao modelo tradicional-patriarcal de distribuição das funções domésticas, como também de algumas mudanças práticas associadas a transformações nas trajetórias laborais de mulheres e homens. Palavras chave: Pais e mães profissionais; relações de gênero; distribuição de tarefas domésticas; parentalidade; trabalho doméstico.

Consuelo Campos Campos (consuelocamposcampos@gmail.com) es socióloga de la Universidad de Concepción, Chile. Memorista Proyecto FONDECYT n 11130379 "Hacia la configuración de nuevas masculinidades: relaciones de género y arreglos domésticos en las familias del Concepción urbano". Memoria titulada: Relaciones de género en hogares de padres y madres profesionales: organización del trabajo doméstico; parentalidad y toma de decisiones, evaluada con la máxima distinción. Expositora en Congreso Chileno de Sociología, Octubre 2014, La Serena, Chile. 
Lucía Saldaña Muñoz (lusaldana@udec.cl) es socióloga, Magíster en Estudios Sociales y Políticos Latinoamericanos, Doctor of Philosophy en Sociología. Profesora Asistente Departamento de Sociología, Universidad de Concepción. Docente carrera de Sociología y Magíster en Investigación Social y Desarrollo, Depto. Sociología. Líneas de investigación: Sociología del Género y del Trabajo, Infancia, Medición de la Pobreza y Políticas Públicas, Desarrollo, Metodologías Cualitativas de Investigación. Investigadora Responsable Proyecto FONDECYT n' 11130379 "Hacia la configuración de nuevas masculinidades: relaciones de género y arreglos domésticos en las familias del Concepción urbano". (Noviembre 2013Octubre 2016). Financiamiento CONICYT, Chile.

18 Revista Estudos Feministas, Florianópolis, 26(2): e42931 